\title{
Análise Comparativa do Índice de Sucesso dos Implantes Osteointegrados com e sem a Utilização de PRP, no Protocolo de Fixação
}

\section{Comparative Analysis of the Index of Success of Implantations with Osteointegrations with and without the Use of PRP, in the Protocol of Setting}

\author{
Feis Feres Junior ${ }^{1}$; Euloir Passanezi²; Sebastião Luiz Aguiar Greghi \\ Adriana Passanezi ${ }^{4}$
}

Resumo

\begin{abstract}
O presente trabalho refere-se ao levantamento de dados de 1267 prontuários do CID - Centro de Implantes Dentários de Londrina. Os resultados de sucessos e perdas de implantes ósseo-integrados foram anotados e, a seguir, separados por marca do implante FOB-USP e ACTIVE, este com dois tipos de superfície (lisa ou jateada). Também se verificou se houve ou não utilização de PRP no protocolo de fixação.Foi analisado o total de 1572 implantes, em 642 dos quais foi utilizado o PRP no protocolo de fixação. Ocorreram 16 perdas, representando um percentual de sucesso de 97,51\%. Em 930 implantes, não foi utilizado o PRP e houve 66 perdas, demonstrando um índice de sucesso de $92,90 \%$. Os resultados foram discutidos à luz da literatura atual, e pode-se concluir que o PRP empregado no protocolo de fixação de implantes conduz a menor perda de implantes ósseo-integrados, aumentando o índice percentual de sucesso de maneira geral. A influência do PRP no índice de sucesso de implantes ósseo-integrados é significativamente mais marcante na maxila que na mandíbula; o PRP representa material promissor nos processos de reconstrução óssea de modo geral, sendo recomendável o seu emprego em situações definidas de colocação de implantes.

Palavras-chave: Implantes. PRP (Plasma Rico em Plaquetas). IGF (Fator de Crescimento Derivado da Insulina). PDGF (Fator de Crescimento Derivado de Plaquetas). TGF-ß (Fator de Crescimento Transformador- ßeta).
\end{abstract}

\footnotetext{
1 Professor Assistente da Disciplina de Estomatologia do Departamento de Medicina Oral e Odontologia Infantil da Universidade Estadual de Londrina e Mestrando do Programa de Periodontia da Faculdade de Odontologia de Bauru - USP.E-mail: drfeis@ onda.com.br

2 Professor Titular da Disciplina de Periodontia da Faculdade de Odontologia de Bauru - USP.

3 Professor Doutor da Disciplina de Periodontia da Faculdade de Odontologia de Bauru - USP.

4 Professora Doutora da Disciplina de Periodontia da Faculdade de Odontologia de Bauru - USP.
} 


\begin{abstract}
This work deals with the data gathering of 1267 dental records from CID - Center of Dental Implants in Londrina, evaluating the success and loss results of osteo-integrated implants and separating them by trademark of the implant FOB - USP and ACTIVE (this one with two types of surface: smooth and sandblasted) and whether the PRP was used or not in the protocol of setting. One thousand five hundred and seventy-two implants were analyzed. In 642 of them the PRP was used in the protocol of setting and there were 16 losses which represent a success percentage of $97,51 \%$. In 930 implants the PRP was not used and there were 66 losses, showing a success index of 92,90\%. The results were discussed based on the current literature, and it was concluded that the PRP used in the protocol of implant setting leads to a loss reduction of the osteo-integrated implants, increasing the success index; the influence of the PRP in the success index of osteo-integrated implants is more significant in the maxilla than in the mandible; the PRP represents a promising material in the processes of bone reconstruction in a general sense, being its use recommended in certain situations of implant settings. Key words: Implants. PRP (Plateled Growth Factor). IGF(Insulin Derived Growth Factor). PDGF (Platelet Derived Growth Factor). TGF-ß(Transformator Growth Factor- ßeta).
\end{abstract}

\section{Introdução}

Os implantes ósseointegrados surgiram como uma alternativa para o tratamento do edentulismo, e como tal, são amplamente estudadas e pesquisadas as razões de seu sucesso, que ocorre através da osseointegração.

Albrektsson e Sennerby (1990), definem a osseointegração como uma interface na qual há contato direto da superfície do implante com o tecido ósseo. Não há a interposição de tecido mole, à luz da microscopia ótica, o que permite uma relação implante-osso harmônica. Os resultados dos implantes odontológicos são significativos, alcançando uma taxa de sucesso de $95 \%$ de permanecia ósseointegrados após 2 anos.

O índice de sucesso do tratamento dependerá da qualidade óssea da região as quais serão instalados. Jaffin e Berman (1991), afirmaram que o índice de sucesso quando fixados em osso tipo I (osso cortical), tipo II (com grande camada cortical e pouco esponjosa) tipo III (com pouco cortical e muita camada esponjosa) é de $97 \%$ e em osso tipo IV (esponjoso) é de $65 \%$. Na tentativa de aumentar esse índice de sucesso, vários estudos são feitos sobre a superfície destes materiais, principalmente o titânio, o qual pode ter uma superfície lisa ou jateada por tratamento ácido.
Nesta busca de melhorar os já significativos resultados da osseointegração, o PRP (Plasma Rico em Plaquetas), por meio de seus fatores de crescimento ósseo, mostra-se capaz de acelerar o tempo de cicatrização dos enxertos ósseos.

Este trabalho analisará o uso do PRP no protocolo de fixação dos implantes, comparando os resultados de dois grupos de pacientes do CID - Centro de Implantes Dentários de Londrina - PR, sendo em um dos grupos usado o PRP no alvéolo cirúrgico. O trabalho também analisa os resultados de duas marcas diferentes de implantes nacionais, bem como, numa mesma marca, o desempenho de implantes com e sem superfície tratada (lisos e rugosos).

\section{Revisão de Literatura}

Lynch et al. (1989), descreve o plasma rico em plaquetas (PRP) como um produto derivado do sangue autógeno por processo laboratorial, colhido em período pré-operatório e rico em fatores de crescimento originários dos grânulos a-plaquetários.

Outros nomes do PRP, são, plasma autógeno de plaquetas, plasma enriquecido com plaquetas, plasma rico em fatores de crescimento, concentrado de plaquetas, ou ainda, gel de plaquetas (ANITUA, 1999; LYNCH, 1989; MARX, 1989; WHITMAN, 1997). 
O plasma rico em plaquetas é um produto orgânico, atóxico e não imunorreativo, que tem sido utilizado para acelerar os caminhos da cicatrização da ferida cirúrgica (ANITUA, 1999; LYNCH, 1989; MARX, 1998), a partir de vários fatores de crescimento nele presente (HOWELL, 1997; WHTIMAN, 1997).

\section{Fatores de Crescimento do Plasma Rico em Plaquetas}

Os fatores de crescimento são polipeptídios da classe dos mediadores biológicos naturais que exercem vários efeitos sobre os processos de reparo e regeneração, sendo responsáveis pela regulação de diversos eventos celulares associados à regeneração tecidual (GIANNOBILE, 1999).

Graves e Cochran (1994) afirmam que fatores de crescimento polipeptídicos são modificadores biológicos naturais que regulam eventos envolvidos no reparo tecidual, tais como síntese de DNA, quimiotaxia, diferenciação e síntese de matriz.

Os principais fatores de crescimento derivados dos grânulos a-plaquetários são: fator de crescimento derivado de plaquetas (PDGF), fator de crescimento similar à insulina (IGF-I) e fator transformador de crescimento beta (TGF-b) (ANITUA, 1999; LYNCH, 1991; MARX, 1999).

\section{IGF Fator de Crescimento Similar a Insulina}

Trata-se de um fator que, durante a formação óssea, é secretado pelos osteoblastos, com a finalidade de aumentar a osteogênese e acelerar a deposição óssea (MARX, 1999; HOCK, 1999; GIANNOBILE, 1999; CANALIS, 1980). Ele está presente na matriz óssea sob a forma de IGF-I e IGF-II (CANALIS; MCCARTHY; CENTRELLA, 1998).

Tanto o IGF-I com o IGF-II, compartilham homologia estrutural com a pró-insulina e desempenham funções similares (CANALIS, 1980; CANALIS; MCCARTHY; CENTRELLA, 1998; GRAVES; COCHRAN, 1994).
Os IGFs são mitogênicos para as células de linhagem osteoblásticas e estimuladores de osteogênese, a partir dos osteoblastos diferenciados já existentes (MARX, 1999; LYNCH, 1989). Foram descritos pela primeira vez na literatura por Rinderknecht e Humbel (1976), demonstrou a homologia de dois polipeptídios do plasma humano com a cadeia de insulina.

Estes trabalhos provam a participação de IGF-I e IGF-II na diferenciação de células competentes, como também na migração, proliferação de células, síntese e secreção dos produto que caracterizam as linhagens celulares especificas, no caso osteoblastos. Desse modo, cabe-lhes regular a formação óssea por via autócrina ou parácrina (GIANNOBILE, 1999), com elevação da síntese de DNA, de osteocalcina e da atividade de fosfatase alcalina (CANALIS; MCCARTHY; CENTRELLA, 1988; HOCK; CENTRELLA; CANALIS, 1988; MCCARTHY; CENTRELLA; CANALIS, 1989).

\section{Fator de Crescimento Derivado de Plaquetas (PDGF)}

Ross et al. (1974), identificaram, pela primeira vez, os fatores de crescimento derivados de plaquetas, como um potente agente mitógeno.

Sant ‘Ana (2001), salientou que, dentre as várias atividade do PDGF no metabolismo ósseo, estariam incluídos o estimulo da atividade mitogênica e quimiotática para osteoblastos, o aumento do número de células produtoras de colágeno, um período de tempo maio na secreção da quantidade total de colágeno, e o estímulo da resposta ósseo-indutora em enxertos de osso desmineralizado em ratos. Também se verifica a estimulação da síntese de DNA por PDGF e IGF, (embora ela não seja concomitante). Essa estimulação tem caráter complementar nos eventos do metabolismo ósseo de proliferação, quimiotaxia e produção de matriz extracelular. 


\section{Fator de Crescimento Trasformador Beta (TGF-b)}

Os TGF-b estimula a síntese de DNA ósseo e a replicação celular, demonstrando serem os osteoblastos as células mais sensíveis à ação desse fator segundo Canalis, McCarty e Centrella (1988).

Pfeilschifter et al. (1990), estudou a associação entre TGF-b, IGF-I, e PDGF quanto à atuação sobre taxa de aposição óssea. Observou que a conjugação das três substâncias foi capaz de dobrar a taxa de aposição óssea em 48 horas e, ainda, de reverter o efeito inibitório exercido pelo paratormônio (PTH).

Giannobile (1999) relata a importância da interação entre diferentes fatores de crescimento no metabolismo ósseo, salientando que:

a) vários fatores de crescimento foram encontrados na matriz óssea em altas concentrações, incluindo o IGF-I, TGF-b, FGFB(fator de crescimento de fibroblasto) e PDGF;

b) as células ósseas liberam vários tipos de fatores de crescimento;

c) durante o reparo ósseo, houve a expressão temporária de vários genes de fatores de crescimento e seus produtos correspondentes.

Portanto, o emprego do PRP poderia ser uma importante maneira de se promover o uso combinado desses fatores de crescimento.

\section{Estudos Realizados Utilizando Plasma Rico em Plaquetas (PRP)}

Becker et al. (1980), publicaram trabalho no qual era comparado o uso de membrana de polietetrafluoretileno expandido (e-PTFE) combinadas com fatores de crescimento derivados do PRP e osso desmineralizado. O grupo controle utilizava membranas o coágulo; quando do uso de PRP, houve um crescimento significativo.

Marx et al.(1998) apresentou o uso do PRP em conjunto com os enxertos ósseos, aumentando o crescimento de osso.
Weibrich et al. (2002), provaram que a concentração plaquetária de PRP não é influenciada pela idade, apenas pelo sexo, com concentração de 237.500/ micromol no homem, e 272.000/ micromol na mulher.

Shanaman, Filstein e Danesh-Meyer (2001), fizeram um estudo utilizando enxerto ósseo autógeno usando GBR (Regeneração óssea guiada) com e sem PRP. Concluíram que a adição de PRP não alterou a qualidade, nem a quantidade neoformada em comparação a GBR sem PRP.

Agahloo, Moy e Freymiller (2002), analisaram os efeitos do uso do PRP em defeitos ósseos no crânio de coelhos. Quando foi usado osso autógeno e PRP, e somente osso autógeno houve uma maior densidade óssea em relação ao grupo controle.

Weibrich et al. (2002), fez outro trabalho a respeito da relação dos fatores de crescimento do PRP de acordo com sexo e idade. Neste estudo, os autores concluíram não haver diferenças nos fatores de crescimento do PRP em relação a sexo e idade.

\section{Critérios de Sucesso dos Implantes Ósseointegrados}

Os primeiros trabalhos utilizavam como critério de sucesso a permanência dos implantes na boca, sem considerar outras características associadas aos tecidos moles e duro adjacentes.

Schinitman e Schulman (1979), propuseram os seguintes critérios:

a) mobilidade menor que $1,0 \mathrm{~mm}$ em qualquer direção;

b) grau de radiolucidez observado radiologicamente, porém sem definição de fracasso;

c) perda óssea menor que $1 / 3$ da altura do implante;

d) inflamação gengival passível de tratamento, ausência de sintoma de infecção e lesão aos dentes adjacentes, parestesia ou violação do canal mandibular; 
e) estar em função de acordo com esses critérios em $75 \%$ dos casos, por um período mínimo de 05 anos.

f) Albrektson et al. (1986), propuseram os seguintes critérios:

g) imobilidade individual do implante, não conectado à prótese, quando examinado clinicamente;

h) falta de evidência de radiolucidez perimplantar, demonstrada pela radiografia;

i) perda anual óssea de $0,2 \mathrm{~mm}$, após o primeiro ano de utilização dos implantes;

j) ausência de sinais e sintomas irreversíveis e/ou persistentes, tais como: dor, infecção, neuropatias, parestesia ou violação do canal mandibular;

k) percentagem mínima de êxito de $85 \%$ após 05 anos de observação e $80 \%$ ao final de 10 anos de acompanhamento.

1) Em 1988, o National Institute of Dental Research (NIDR) em conjunção com National Institute of Health (NIH) organizaram nos Estados Unidos uma conferência para estabelecer um consenso acerca dos implantes dentários, sugerindo os seguintes critérios:

m) acompanhamento de casos consecutivos;

n) apresentação dos objetivos do estudo com definição clara e precisa dos critérios de sucesso ou falha;

o) descrição da população em estudo e dos critérios de seleção dos pacientes;

p) padronização com a maior extensão possível das medidas dos resultados obtidos com o tratamento, aumentado a confiabilidade dos dados;

q) seleção adequada do tamanho da amostra;

r) relato de todos os pacientes que abandonaram a avaliação;

s) registro de todas as falhas, desde à inserção dos implantes; t) documentação e acompanhamento de cada falha;

u) utilização de métodos de análise padronizados, incluindo a "tabela de quatro campos",

v) evitar extrapolação dos dados a populações similares às do estudo sob condições experimentais parecidas.

\section{Proposição}

Diante da literatura atual a respeito dos implantes ósseointegrados como elementos fundamentais na técnicas mais recentes de reabilitação bucal, aprofundamento de estudos sobre fatores de crescimento ósseo e análise das performances dos vários tipos de implantes, com vários tipos de superfícies, este estudo foi realizado com os seguintes objetivos:

1. Avaliar os desempenhos de duas marcas de implantes (FOB-USP - ACTIVE), com dois tipos de superfícies (Lisa e Jateada), com e sem a utilização de PRP no protocolo de fixação.

2. Sugerir uma modificação no protocolo convencional de fixação de implantes ósseointegrados (uso de PRP).

\section{Material e Métodos}

Para realização deste projeto, foram feitos levantamentos de dados de 1267 prontuários do CID - Centro de Implantes Dentários de Londrina, considerando o número de implantes fixados, a região da boca (anterior ou posterior, maxila ou mandíbula), o tamanho do implante, a marca do implante FOBUSP e ACTIVE, este com dois tipos de superfície (lisa ou jateada), além, é claro, se houve ou não uso do PRP no protocolo de fixação.

Nos casos em que se fez uso do PRP, a coleta e preparo do material foi feito previamente à cirurgia de instalação dos implantes em si, respeitando os seguintes procedimentos: 
- coleta de $20 \mathrm{ml}$ de sangue venoso do paciente, no máximo 24 horas antes da cirurgia, em laboratório próprio para este fim, e seguindo todos os preceitos de controle de infecção, conforme o protocolo de Aldecoa, 1996; -separação do material (sangue) em 4 frascos de $5 \mathrm{ml}$, cada um contendo uma gota de citrato de sódio a $(18,8 \mathrm{~g} /$ dl) com a função de anticoagulante, (Fig. 2);

- centrifugação das amostras em centrífuga FANEN a 1400rpm(rotações por minuto), durante 10 minutos, com aceleração gradual começando da velocidade zero e desaceleração também gradual do aparelho, até a velocidade zero (Fig. 3), possibilitando a separação dos componentes da amostra em camadas distintas;

- pipetagem das camadas superficiais de 500il de cada frasco, formando o PPP (plasma pobre em plaquetas) (Fig. 4 e 5);

- pipetagem da segunda camada também de 500il, formando o PRP(plasma rico em plaquetas) (Fig. 4);

- pipetagem da terceira camada, agora de 600ìl, formando o $\mathrm{PRP}+($ plasma riquíssimo em fatores de crescimento ósseo) (Fig. 4);

- após o preparo do leito cirúrgico com a última broca, aspirou-se a cavidade e cuidadosamente aplicou-se o conteúdo adequado do gel de PRP (Fig. 7);

- o restante de PRP foi utilizado junto com eventuais enxertos ósseos com material autógeno, recolhido por meio de coletor ósseo, e/ou na área de sutura dos tecidos moles.

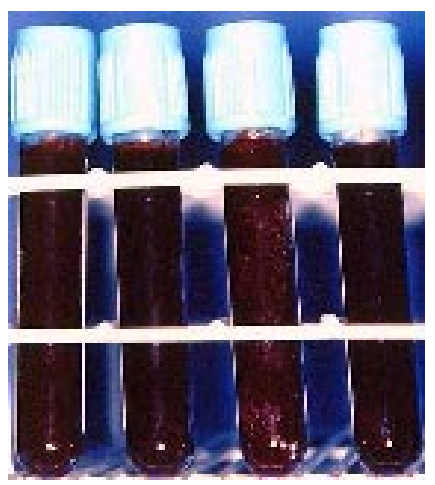

Figura 1. Frascos de $5 \mathrm{ml}$ contendo as amostras do sangue coletado do paciente acrescido de anticoagulante.

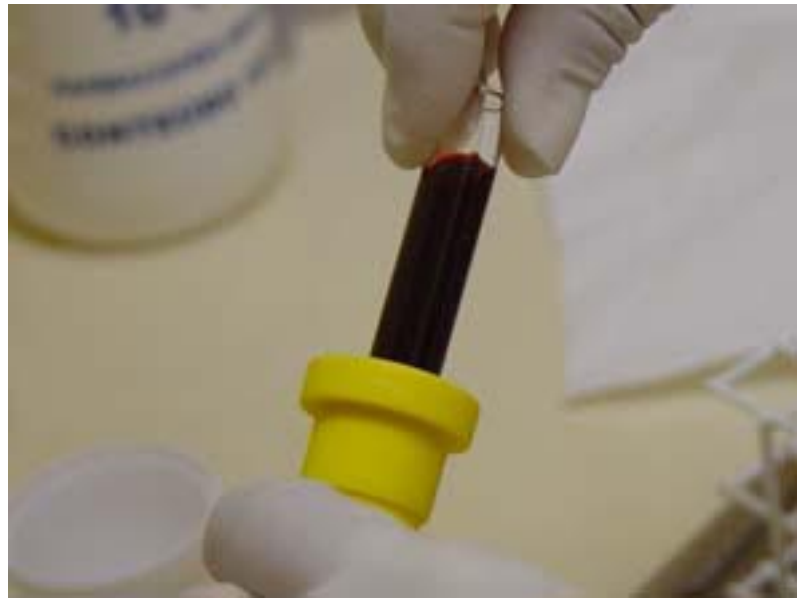

Figura 2A. Fixação dos frascos com as amostras de sangue no suporte próprio para suspensão na centrífuga;

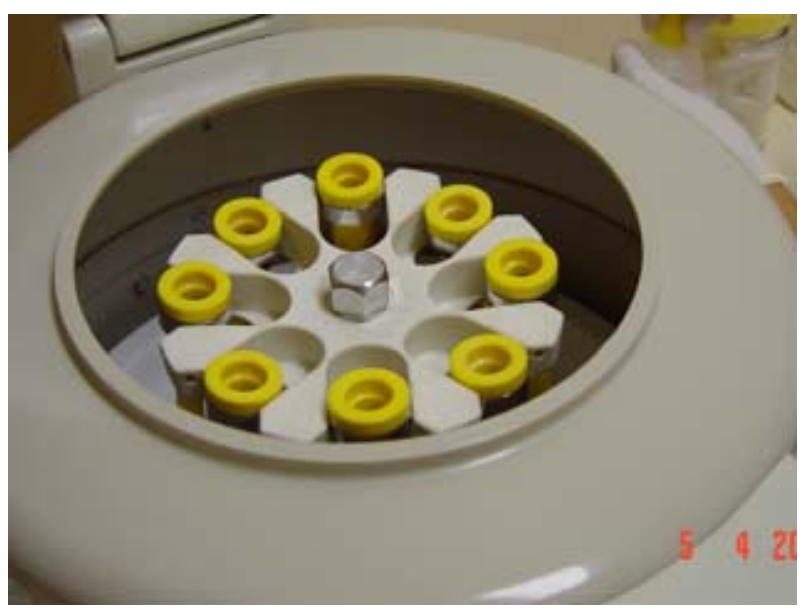

Figura 2B. Posição dos frascos em suspensão na centrífuga;

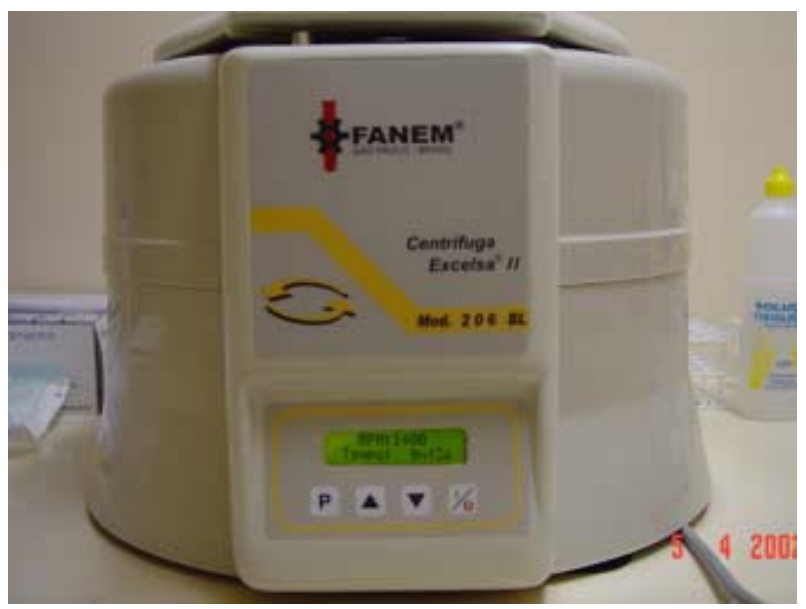

Figura 2C. Vista frontal da centrífuga, identificando os controles de funcionamento. 


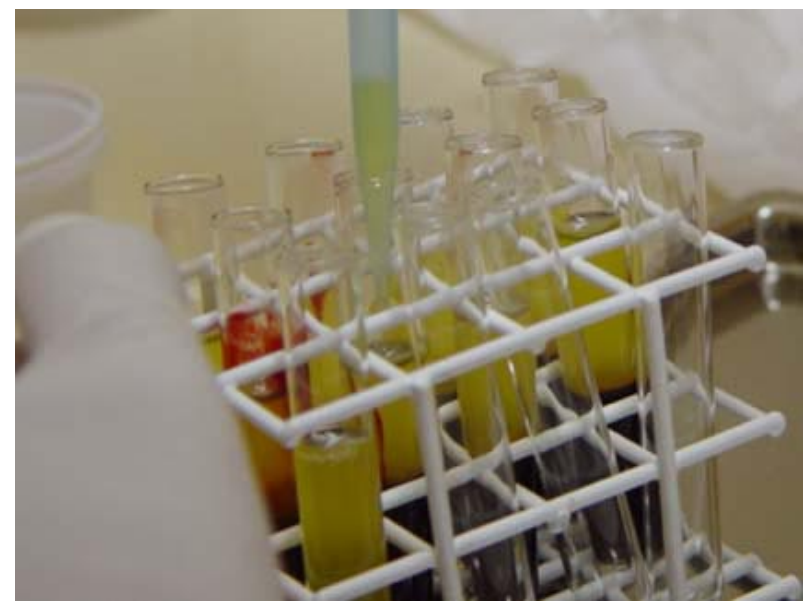

Figura 3. Amostras centrifugadas posicionadas em suporte apropriado. Observe a extremidade da pipeta absorvendo a $1^{\mathrm{a}}$ camada da suspensão (PPP).

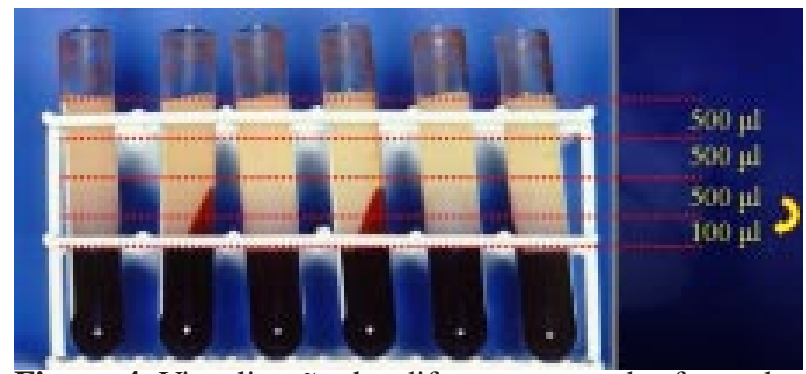

Figura 4. Visualização das diferentes camadas formadas a partir da centrifugação do sangue, identificando-se as camadas contendo as plaquetas.

Os conteúdos pipetados da primeira camada de cada frascos foram desprezados, enquanto os da $2^{\mathrm{a}}$ e $3^{\text {a }}$ camadas foram todos misturados em uma cubeta cirúrgica e ativados, no momento da cirurgia, com $3 \mathrm{ml}$ de cloreto de cálcio (solução 10M), como forma de reconstituição da suspensão, afim de permitir a sequiência da cascata da coagulação (Fig. 6);

Foram considerados todos os implantes anotados nos prontuários, bem como as perdas, sendo que a condição para ser considerado sucesso, foi estar estável e sem sintomatologia na boca há pelo menos um ano, com ou sem carga.

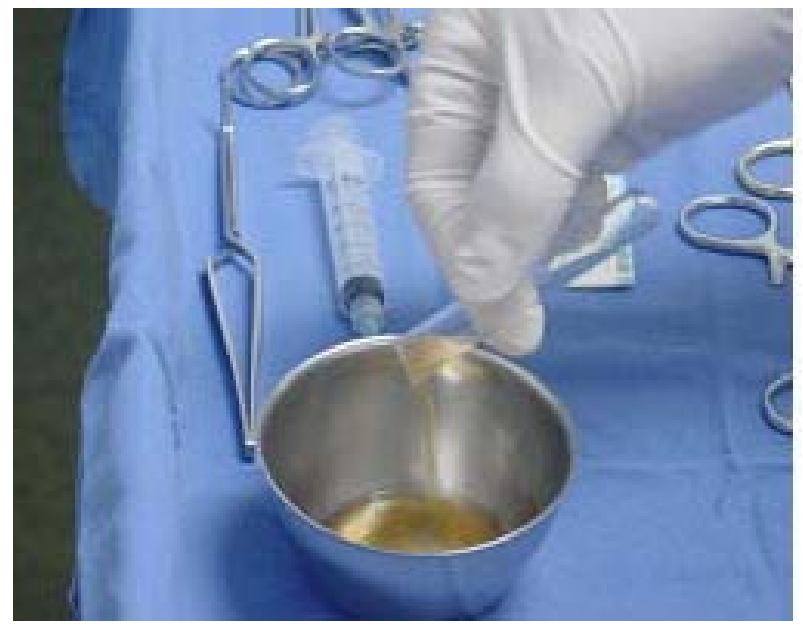

Figura 5A. Mistura dos conteúdos da $2^{\mathrm{a}}$ e $3^{\mathrm{a}}$ em cubeta cirúrgica;

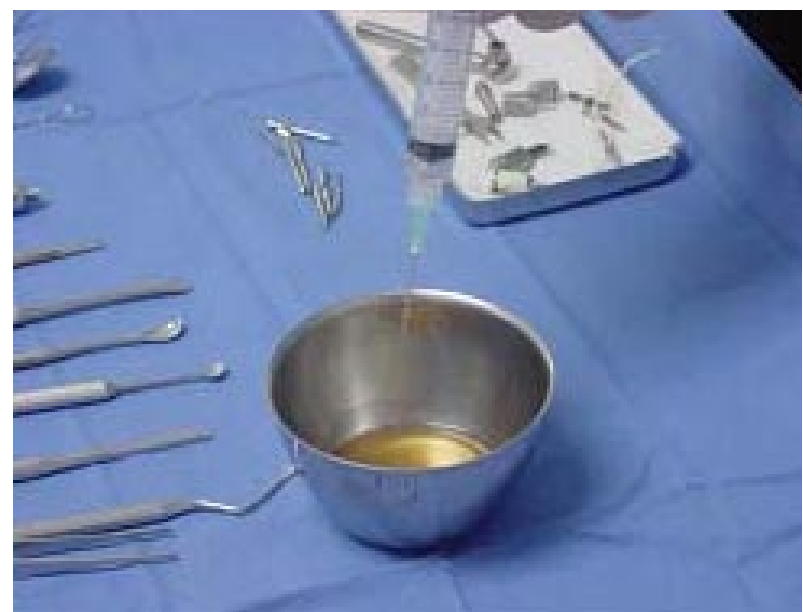

Figura 5B. Adição de $3 \mathrm{ml}$ de solução $10 \mathrm{M}$ de cloreto de cálcio. Observe que o conjunto encontra-se no campo cirúrgico, ilustrando a operação no momento cirúrgico;

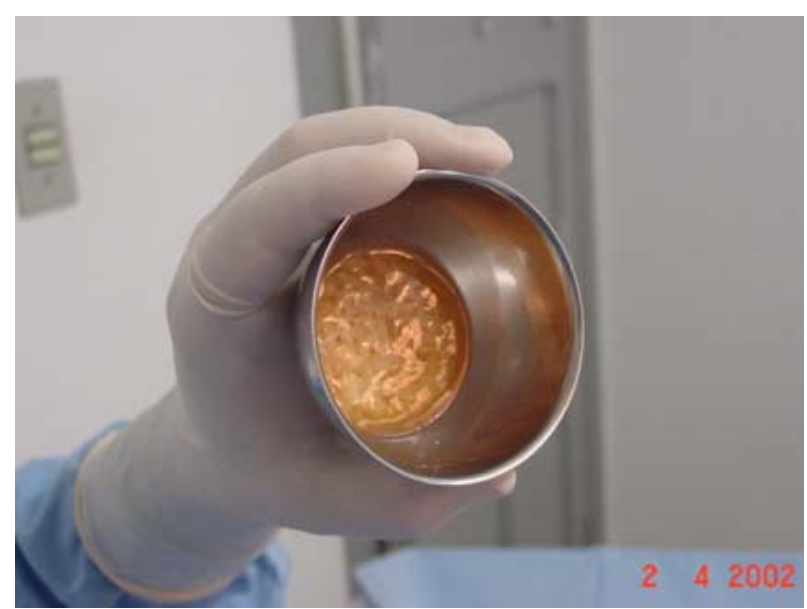

Figura 5C. Ilustração da adesividade do PRP ativado junto às paredes da cubeta, que se encontra inclinada porém o material não escoa; 


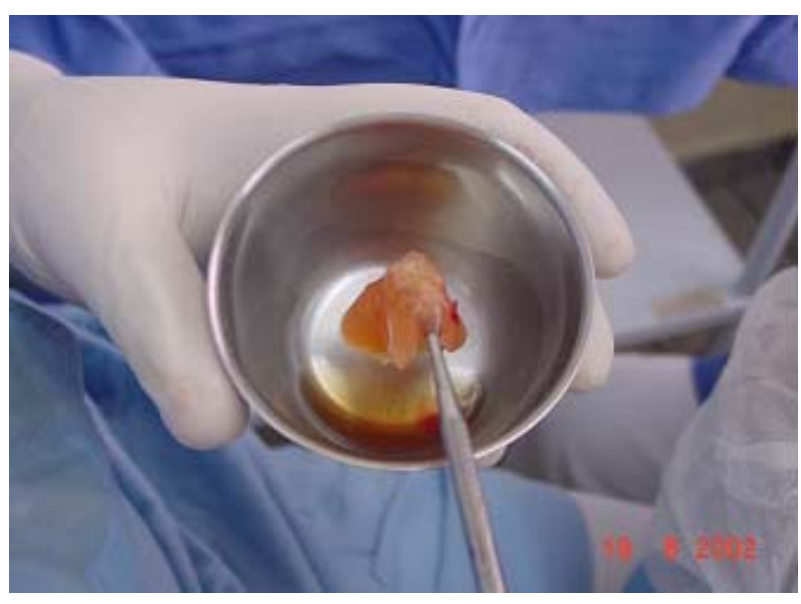

Figuras 5D e 5E. Vista da tomada do PRP com destaca periósteo, podendo se verificar um estado de agregação e consistência.

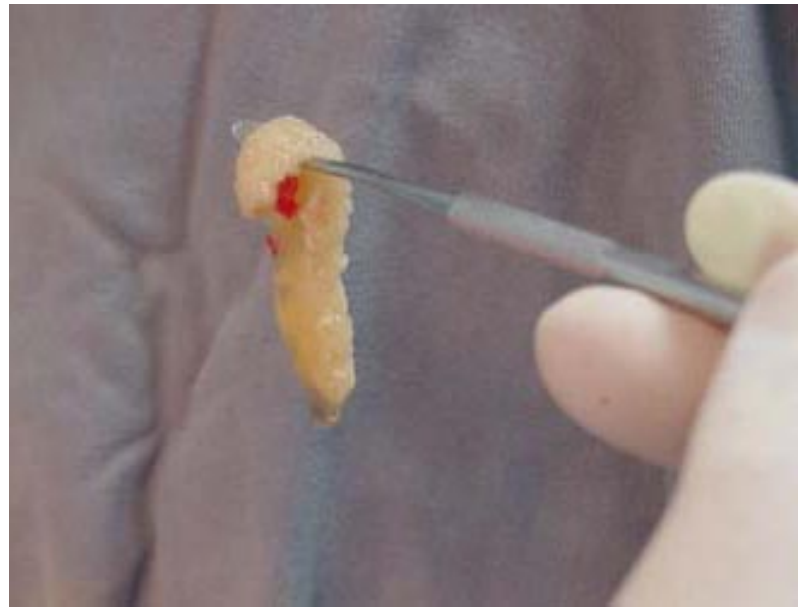

Figura 6. Momento da aplicação do gel de PRP preenchendo a loja cirúrgica para instalação do implante. A imagem ilustra, também, a facilidade de manuseio do material.

O protocolo de fixação seguiu o esquema padrão do CID, que respeitou os princípios gerais de Bränemark et al. (1983) e vem sendo usado com sucesso por tempo prolongado.

No pós-operatório imediato, foram ministradas 40 gotas de dipirona sódica e feita uma primeira aplicação de Laser terapêutico na media de 3 joules por implante. As aplicações foram repetidas com 24, 36,48 e 72 horas com o objetivo de melhorar o pósoperatório.

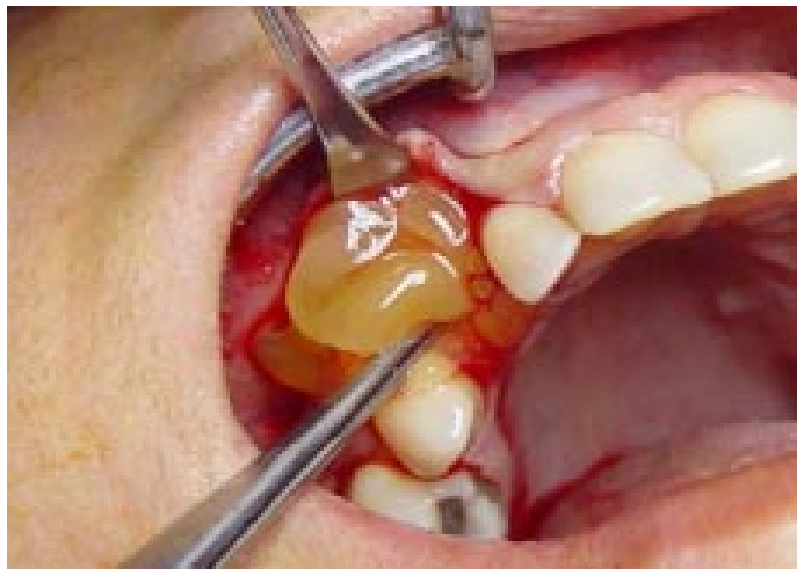

Figura 7. Aplicação de laser terapêutico no pós operatório imediato, observe os óculos de proteção tanto no operador quanto no paciente, prevenindo lesões na retina.

As orientações pós-operatórias foram passadas por escrito ao paciente e encontram-se anexas.

\section{Resultados}

Os resultados estão apresentados em forma de gráficos e tabelas, e os números individualizados e detalhados estão anexos, no apêndice.

Para permitir a visualização instantânea dos dados, após a tabulação dos resultados nas tabelas, foi elaborada a apresentação gráfica desses resultados para cada uma das variáveis em análise.

Todos os números sofreram tratamento estatístico e dependendo das quantidades foi utilizado o teste do qui-quadrado ou teste exato de Fisher, sendo que os resultados da análise seguem após cada amostragem. Quando o valor "p" foi menor do que 0,05 , o resultado foi significante do ponto de vista estatístico. 


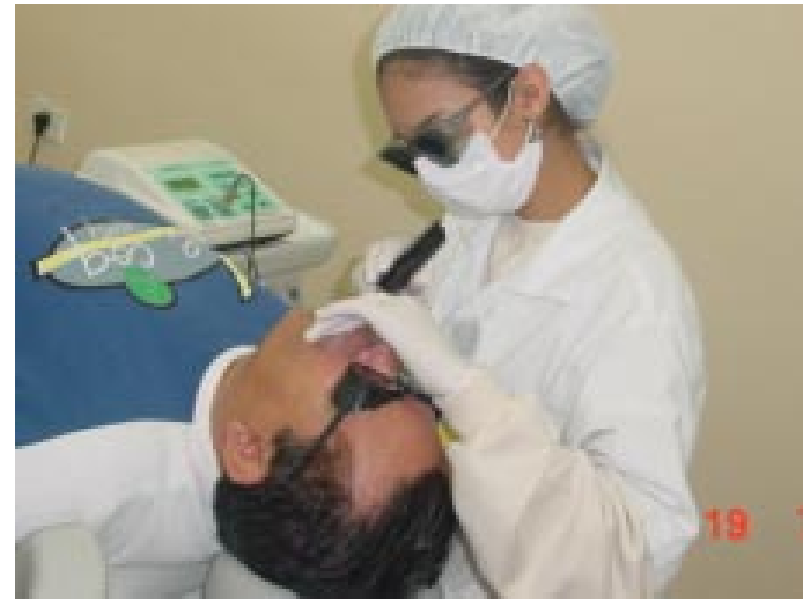

1. N. ${ }^{\circ}$ de Implantes FOB-USP: 580, 555 sem PRP 40 perdas - 92,79\% sucesso, 25 com PRP nenhuma perda $-100 \%$ sucesso, $\mathrm{x} 2=1,94 \mathrm{p}=0,164$, Não significante.

2. N. ${ }^{\circ}$ de Implantes ACTIVE: 569, 325 sem PRP 20 perdas - 93,85\% sucesso, 244 com PRP 05 perdas - 97,95\% sucesso, $x 2=5,59 p=0,018$, Significante.

3. N. ${ }^{\circ}$ de Implantes ACTIVE JATEADO: 423, 50 sem PRP 06 perdas - 88\% sucesso, 373 com PRP 11 perdas $-97,05 \%$ sucesso, $\mathrm{x} 2=9,36 \mathrm{p}=0,002$, Significante.

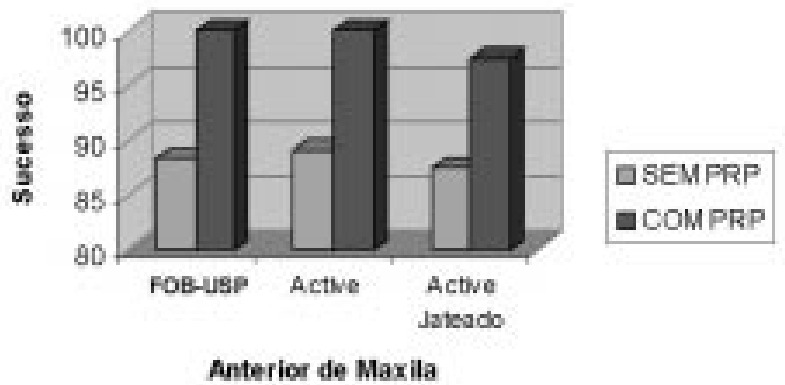

Figura 9. Gráfico de desempenho das marcas na região anterior da maxila.

FOB-USP: 155 implantes sem PRP - 18 perdas - 88,39\% sucesso, 03 implantes com PRP - nenhuma perda - 100\% sucesso, Fisher $\mathrm{p}=1,000$, Não significante. Active: 55 implantes sem PRP - 06 perdas - 89,09\% sucesso, 45 implantes com PRP - nenhuma perda - 100\% sucesso, Ficher $\mathrm{p}=0,031$, Significante. Active Jateado: 8 implantes sem PRP - 01 perda - 87,50\% sucesso, 76 implantes com PRP - 2 perdas - 97,37\% sucesso, Fisher $p=0,262$, Não significante.

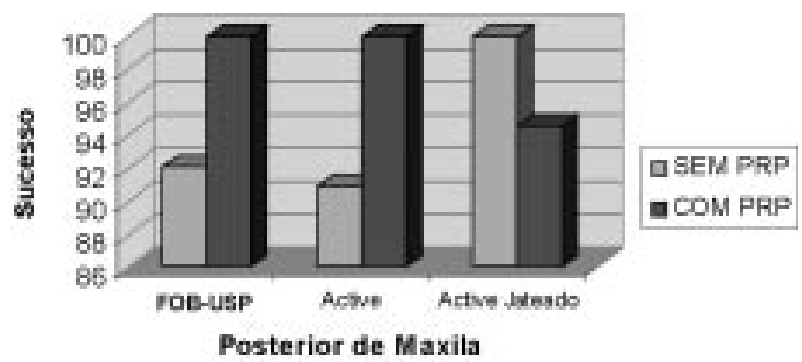

Figura 10. Gráfico de desempenho das marcas na região posterior da maxila.

FOB-USP: 101 implantes sem PRP - 08 perdas - 92,08\% sucesso, 01 implante com PRP - nenhuma perda - 100\% sucesso. Fisher $\mathrm{p}=1,000$, Não significante. Active:55 implantes sem PRP - 05 perdas - 90,91\% sucesso, 42 implantes com PRP - nenhuma perda - 100\% sucesso, Fisher $\mathrm{p}=0,054$, Não significante. Active Jateado: 06 implantes sem PRP - nenhuma perda - 100\% sucesso, 55 implantes com PRP - 03 perdas - 94,55\% sucesso, Fisher $\mathrm{p}=1,000$, Não significante.

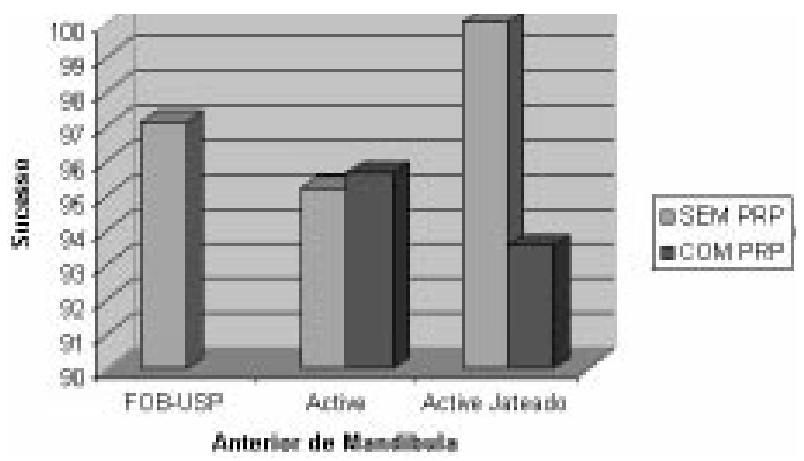

Figura 11. Gráfico de desempenho das marcas na região anterior da mandíbula.

FOB-USP: 70 implantes sem PRP - 02 perdas - 97,14\% sucesso. Nenhum implante com PRP, Como não houve implante com PRP, não há como fazer analise estatística. Active: 42 implantes sem PRP - 02 perdas - 95.24\% sucesso, 23 implantes com PRP - 01 perda - 95,65\% sucesso. Fisher $\mathrm{p}=1,000$, Não significante. Active Jateado: 04 implantes sem PRP - nenhuma perda - 100\% sucesso, 31 implantes com PRP - 02 perdas - 93,55\% sucesso.Fisher $\mathrm{p}=1,000$, Não significante. 


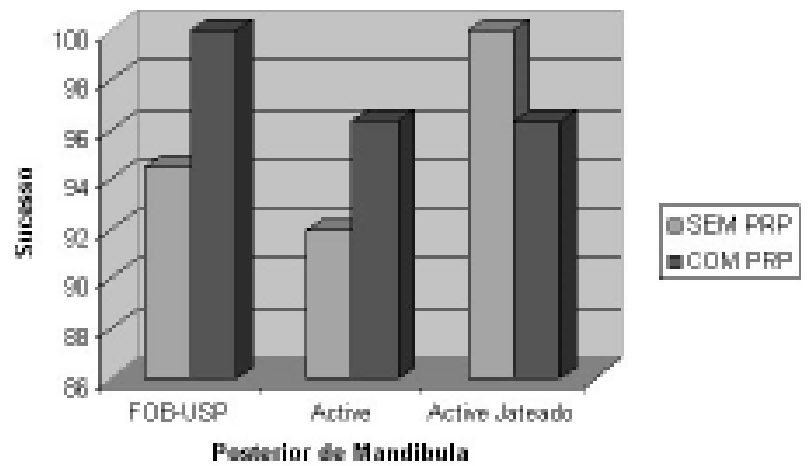

Figura 12. Gráfico de desempenho das marcas na região posterior da mandíbula.

FOB-USP: 145 implantes sem PRP - 08 perdas - 94,48\% sucesso. 03 implantes com PRP - nenhuma perda - 100\% sucesso, Como não houve implante com PRP, não há como fazer analise estatística. Active: 87 implantes sem PRP 07 perdas - 91,95\% sucesso, 55 implantes com PRP - 02 perdas $-96,36 \%$ sucesso. Fisher $p=0,482$, Não significante. Active Jateado: 05 implantes sem PRP - nenhuma perda $100 \%$ sucesso, 82 implantes com PRP - 03 perdas - 96,34\% sucesso. Fisher $\mathrm{p}=1,000$, Não significante.

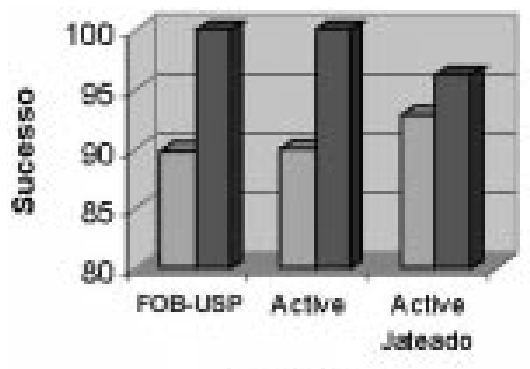

口SEM PRP COM PRP

MAXILA

Figura 13. Gráfico de desempenho das marcas na região da maxila.

FOB-USP: 256 implantes sem PRP - 26 perdas 89,85\% sucesso, 04 implantes com PRP - nenhuma perda - 100\% sucesso. Fisher $\mathrm{p}=1,000$, Não significante. Active: 110 implantes sem PRP - 11 perdas 90\% sucesso. 87 implantes com PRP - nenhuma perda - $100 \%$ sucesso. Fisher $\mathrm{p}=0,001$, Significante. Active Jateado: 14 implantes sem PRP - 01 perda $92,86 \%$ sucesso, 131 implantes com PRP - 05 perdas - 96,18\% sucesso. Fisher p=0,450, Não significante.

TOTAL: 380 implantes sem PRP - 38 perdas $90 \%$ sucesso, 222 implantes com PRP - 05 perdas 97,75\% sucesso, $\mathrm{x} 2=$ $12,68 \mathrm{p}=0,0004$, Significante.

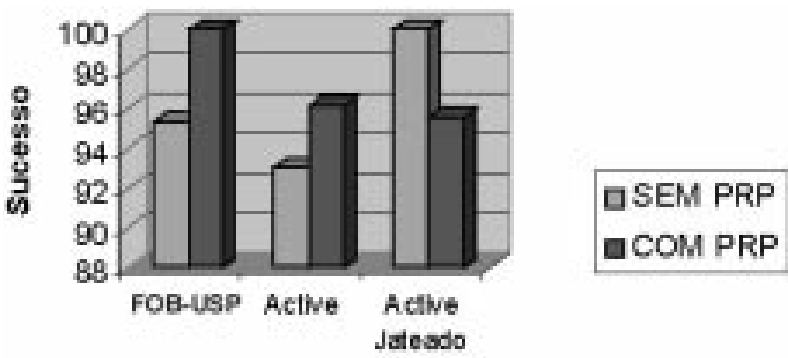

MANDIBBULA

Figura 14. Gráfico de desempenho das marcas na região da mandíbula.

FOB-USP: 215 implantes sem PRP - 10 perdas 95,35\% sucesso, 03 implantes com PRP - nenhuma perda - 100\% sucesso. Fisher $\mathrm{p}=1,000$, Não significante. Active: 129 implantes sem PRP - 09 perdas 93,02\% sucesso, 78 implantes com PRP - 03 perdas 96,15\% sucesso. Fisher $\mathrm{p}=0,541$, Não significante. Active Jateado: 09 implantes sem PRP - nenhuma perda - 100\% sucesso, 113 implantes com PRP - 05 perdas 95,58\% sucesso. Fisher p=1,000, Não significante.

TOTAL: 353 implantes sem PRP - 19 perdas 94,62\% sucesso, 194 implantes com PRP - 08 perdas 95,88\% sucesso, $\mathrm{x} 2=0,42 \mathrm{p}=0,516$, Não significante.

A título de ilustração é apresentado o comportamento global dos implantes por arcada sob a forma de gráfico (Figura 15).

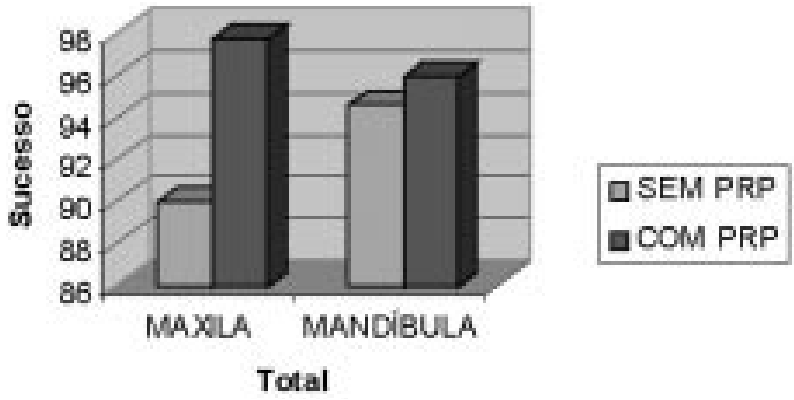

Figura 15. Representação gráfica do comportamento global dos implantes na maxila e mandíbula, deixando evidente a maior variação percentual de sucesso com o uso do PRP na maxila. 


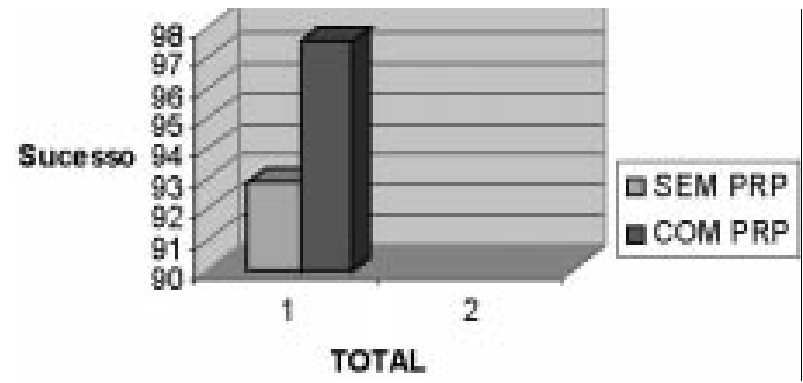

Figura 16. Gráfico de desempenho dos implantes com e sem PRP na maxila e mandíbula.

Total de Implantes sem PRP: 930 - 66 perdas - 92,90\% sucesso: 555 FOB-USP, 325 Active, 50 Active Jateado. Total de Implantes com PRP: 642 - 16 perdas - 97,51\% sucesso: 25 FOB-USP, 244 Active, 373 Active Jateado,

O Teste aplicado é o teste do qui-quadrado cujo resultado foi um valor de 16,29 que dá uma valor de $\mathrm{p}=0,0001$. Como é menor que $5 \%(0,05)$ isto indica uma diferença estatisticamente significante entre as condições com e sem PRP.

\section{Discussão}

Desde a introdução do sistema Branemark et al.(1969), ou seja, dos implantes osseointegrados, algumas inovações no protocolo original foram introduzidas, afim de, se melhorar as condições para alcançar os anseios básicos da população sequiosa de seus benefícios, qual seja o restabelecimento das suas necessidades odontológicas em nível funcional, estético, fonético e psicológico.

A necessidade de volume ósseo adequado para inserção e posicionamento do implante é um dos principais requisitos para a colocação deste em um paciente. Essa necessidade de qualidade e quantidade óssea, induz a uma busca por um melhor resultado na osseointegração o que, exalta o papel dos mediadores da fisiologia óssea, sob a forma de fatores de crescimento, que aumentam a ação dos osteoblastos, formando osso. Nesse contexto, os fatores mais importantes são, PDGF, IGF e TGFb; os quais são encontrados no PRP.
Por meio de estudos dos resultados estatísticos, mostra-se que a variação significativa deve ser situada na escala de 90 a $100 \%$ de sucesso, portanto com variação percentual de $10 \%$, pode se implicar que a variação de 4,61\% de diferença no índice de sucesso obtido com o emprego do PRP, em realidade representa variação efetiva de $46,1 \%$ a mais dentro desta faixa critica de $10 \%$, mostrando que a variação é altamente significativa, como ilustrado pelo valor crítico do teste do qui-quadrado de 0,0001.

\section{Conclusão}

Os dados coletados e analisados para a amostra e a metodologia empregadas permitem chegar às seguintes considerações conclusivas:

1. O PRP empregado no protocolo de fixação de implantes conduz a menor perda de implantes osseointegrados, aumentando o índice percentual de sucesso de maneira geral.

2. A influência do PRP no índice de sucesso de implantes osseointegrados é significativamente mais marcante na maxila que na mandíbula.

3. O PRP representa material promissor nos processos de reconstrução óssea de modo geral, sendo recomendável o seu emprego em situações definidas de colocação de implantes.

\section{Referências}

AGHALLO, T. L; MOY, P. K; FREYMILLER, E. G. Investigation of platelet-rich plasma in rabbit cranial defects. A pilot study. Journal of Oral \& Maxillofacial Surgery, Philadelphia, v.60, n.10, p.1176-81, out. 2002.

ALBREKTSSON, T.; ZARB, G. A.; WORTHINGTON, P.; ERIKSSON, A. R. The long-term efficacy of currently used dental implants: a review and proposed criteria of success. The International Journal of Oral \& Maxillofacial Implants, Lombard, v.1, n.1, p.11-25, jan./feb. 1986.

ALBREKTSSON, T.; SENNERBY, L. Direct bone anchorage of oral implants: clinical and experimental considerations of the concept of osseointegration. The International Journal of Prosthodontics, Lombard, v.3, n.1, p.30-41, jan./feb. 1990. 
ANITUA, E. A. Um novo enfoque na cirurgia e prótese sobre implante. [S.I: s.n], 1999.

BECKER, W. et al. Clinical and microbiologic findings that may contribute to dental implant failure. The International Journal of Oral \& Maxillofacial Implants, Lombard, v.9, n.6, p.31-38, nov./dec. 1994.

BRÄNEMARK, P. I.; BRÄNEMARK, P. I.; BREINE, U.; ADELL, R.; HANSSON, B. O.; LINDSTRÖM, J.; OHLSSON, A. Intra-osseous anchorage of dental prostheses. Scandinavian Journal of Plastic and Reconstructive Surgery, Stockholm, v.3, p.81-100, 1969.

BRÄNEMARK, P. I. Osseointegration and its experimental background. The Journal of Prosthetic Dentistry, Saint Louis, v.50, n.3, p.399-410, set. 1983.

CANALIS, E. Effect of insulin like growth factor I on DNA and protein synthesis in cultured rat calvaria. Journal of Clinical Investigation, New York, v.66, n. 4, p.709-719, oct. 1980.

CANALIS, E.; MCCARTY, T.; CENTRELLA, M. Isolation and characterization of insulin-like growth factor I (somatomedin-C) from cultures of fetal rat calvariae. Endocrinology, Bethesda, , v.122, p.22-7, 1988.

GRAVES, D. T; COCHRAN, D. L. Periodontal regeneration with polypeptide growth factors. In: WILLIAMS, R. C.; YUKNA, R. A.; NEWMAN, M. G. Current opinion periodontology. 2. ed. Philadelfia: Current Science, 1994. cap.18, p.178-186.

GIANNOBILE, W. V. Periodontal tissue engeneering by growth factors. Bone, New York, v.19, p. 235-375, 1999.

HOCK, J. M.; CENTRELLA, M.; CANALIS, E.Insulin-like growth factor I has independent effects on bone matrix formation and cell replication. Endocrinology, Bethesda, v.122, p.254-60, 1988.

HOWELL, T. H.; FIORELLINI, J. P.; PAQUETTE, D. W.; OFFENBACHER, S.; GIANNOBILE W. V.; LYNCH, S. E. A phase I/II clinical trial to evaluate a combination of recombinant human platelet-derived growth factor-BB and recombinant insulin-like growth factor-I in patients with periodontal disease. Journal of Periodontology, Chicago, v.68, n.12, p.1186-93, dec. 1997.

JAFFIN, R. A.; BERMAN, C. L. The excessive loss of Bränemark fixtures in type IV bone: a 5-year analysis. Journal of Periodontology, Chicago, v.62, n.1, p.2-4, jan. 1991.

LYNCH, S. E.; WILLIAMS, R. C.; POLSON, A. M.; HOWELL, T. H.; REDDY, M. S.; ZAPPA, U. E.; ANTONIADES, H. N. A combination of platelet-derived and insulin-like growth factors enhaces periodontal regeneration. Journal of Clinical Periodontology, Copenhagen, v.16, p.545-8, 1989.
LYNCH, S. E.; CASTILLA, G. R.; WILLIAMS, R. C.; KIRITSY, C. P.; HOWELL, T. H.; REDDY, M. S.; ANTONIADES, H. N. The effects of short-term application of a combination of platelet-derived and insulin-like growth factors on periodontal wound healing. Journal of Periodontology, Chicago, v.62, p.458-67, 1991.

LYNCH, S. E. et al. Polypeptide growth factors:Molecular mediators of tissue repair. In: GENCO, R. J. et al. Molecular Pathogenesis of Periodontal Disease. Washington: American Society of Microbiology Press, 1994. p.415-25.

MARX, R. E. et al. Rich Plasma: Growth factors enhancement for bone grafos. Oral Surgery, Tokio, v.85, p.638-46, 1998.

MARX, R. E.; CARLSON, E. R.; EICHSTAEDT, R. M.; SCHIMMELE, S. R.; STRAUSS, J. E.; GEORGEFF, K. R. Platelet rich plasma:growth factor enhancement for bone grafth. Oral surgery, Oral Medicine, Oral Pathology, Saint Louis, v.85, p.638-46, 1998.

MARX R. E. Platelet rich plasma: a source of múltiple autologous growth factors for bone grafts. In: LYNCH S. E.; GENCO, R. J.; MARX, R. E. Tissue Engineering. Applications in Maxillofacial Surgery and Periodontics. Chicago: Quintessence Publishins, 1999. p.71-82.

MCCARTHY, T. L.; CENTRELLA, M.; CANALIS, E. Insulin-like growth factor (IGF) and bone. Connective Tissue Research, New York, v.20, p.277-82, 1989.

MCCARTHY, T. L.; CENTRELLA, M.; CANALIS, E. Constitutive synthesis of insulin-like growth factors II by primary osteoblast: enriched cultures fron fetal rat calvariae. Endocrinology, Bethesda, v.130, p.1303-8, 1992.

PFEILSCHIFTER, J.; OECHSNER, M.; NAUMANN, A.; GRONWALD, R. G.; MINNE, H. W.; ZIEGLER, R. Stimulation of bone matrix apposition in vitro by local growth factors: a comparision between insulin-like growth factor I, platelet derived growth factor, and transferring growth factorsb. Endocrinology, Bethesda, v.127, p.6975,1990 .

RINDERKNECHT, E.; HUMBLE, R. E. Amino-terminal sequences of two peptides from human serum with nonsupressible insulin-like and cell growth promoting activities: evidence for structural homology with insulin chain. Proceedings of the National Academy of Sciences of the United States of America, Washington, v.73, p.43794381, 1976.

ROSS, R. Platelet-derived growth factor. Journal Lancet, Minneapolis, v.1, n.853, p.1179-1182, may 1989.

SANT'ANA, A. C. P. Efeitos da aplicação de diferentes fatores de crescimento (PDGF-BB, IGF-1 e TGF-BI) isolados ou combinados na taxa de ploriferação e na adesão de fibroblastos derivados de ligamento 
periodontal humano a fragmentos radiculares tratados ou não com ácido cítrico e tetraciclina após a raspagem. 2001. 131p. Tese (Doutorado) - Faculdade de Odontologia de Bauru, Bauru, 2001.

SCHNITMAN, P. A.; SHULMAN, L. B. Recommendations of the consensus development conference on dental implants. Journal of the American Dental Association, Chicago, v.98, p.373-7, mar. 1979.
SHANAMAN, R. H.; FILSTEIN, M. R.; DANESHMEYER, M. J. Localized ridge augmentation using guided bone regeneration and platelet-rich plasma. The International Journal of Periodontics and Restorative Dentistry, Lombard, v.21, n.4, p.345-55, 2001.

WEIBRICH, G.; KLEIS, W. K. G.; HAFNER, G.; HITZLER, W. E. Growth factor levels in PRP and correlations with donor, sex, and platelet count. Journal of Cranio-maxillofacial Surgery, Kidlinton, v.30, n.2, p.97-102, apr. 2002. 
